\title{
IODINE IN CHORIO-RETINAL OEDEMA
}

\section{By}

\author{
RICHARD KERRY
}

MONTREAL

THE amount of fluid present in the eye in many cases of retinal detachment is much larger than one would expect that the relatively few retinal capillaries could furnish, and since the chorio-capillaris is the only other probable source of the fluid, one naturally concludes that the objective signs present in this condition are due to choroidal trauma, direct or infective. As retinal oedema, amounting to detachment, is found in cases of choroidal inflammation and, as one of the effects of ligature of the vorticosae is to cause detachment, almost indistinguishable from the traumatic form, it would seem that retinal detachment is ordinarily due to choroidal effusion.

Whatever view one may take of the pathology of this condition, measures to promote absorption of fluid and at the same time to terminate causal inflammation are indicated. There is no more powerful stimulant to cellular metabolism than iodine and the writer has been using this remedy in some recent cases of chorioretinal oedema, with encouraging results.

The first case, a man, aged 40 years, had injured his left eye by collision with the edge of a door, two weeks before his first visit. Examination showed undoubted detachment extending from 4.30 to 6 and flat detachment or oedema to a line running from 3 to 9 o'clock. Vision : larger letters seen misshapen and irregular; large defect in the upper temporal field. Two days after the first injection of iodine the oedema had disappeared and within the week the retina had become reattached. As the swelling lessened it was seen that the inferior nasal artery. had been injured; near the dise it appeared as a white cord while further out it was small and pale pink in colour; corresponding to this injury was a large defect in the upper temporal field. The artery gradually recovered its function and in three months the scotoma, which had invaded the fixation point, had receded so far that it was causing no trouble. Recent reports, two years after the accident, indicate that the eye is acting normally.

The second case, a man, aged 50 years, came in with acute oedema of the right retina with accumulation of fluid at the lower part of the eye. Apparently floating on the fluid were a number of relatively large, buff-coloured spots of exudate, taking their contour principally from the nerve-fibre layer. Vision practically nil. Two days after the first injection the oedema had disappeared 
and the retina looked as though there were choroidal atrophy present, minus pigment changes. Three weeks later there were a few small atrophic spots on the fundus, but central vision was normal, as luckily the macula had not been affected by the exudate. There was history of rheumatism in this case and there was dental sepsis. The blood was not examined but the teeth were attended to.

The third case was a woman, aged 40 years, on whom I had refused to operate for cataract two years previously, because of her wretched general condition. Two weeks before her first visit a finger had been poked with violence into her seeing eye, causing smart external haemorrhage. Examination showed retinal detachment, involving the lower half of this retina and extending to well above the horizontal line. Two days after the first injection there was still some detachment just below the disc, which disappeared during the next few days. As there was central opacity in the lens in this case, the vision obtained, $6 / 12$, was about what one would expect and as near vision was J.1. there was no central retinal defect.

The preparation used in these cases was a solution of iodine in sesame oil (1-40) sterilized on a water-bath. Fifteen minims were given, twice during the first week, once a week later on, with a hypodermic syringe, any convenient site being chosen (not the conjunctiva, as has been done). The injection must be carried well through the skin, otherwise induration results, but intra-muscular injection is not necessary. The syringe must be washed with ether after use to preserve the needle. There are a number of iodine preparations on the market, but on the general therapeutic principle that a compound is active in proportion to the simplicity of its ionization, the simple solution is preferable to the more highly organized molecules contained in tetra-iodo-phenol-phthalein and similar preparations.

Some years ago the writer made a 1-50 colloidal solution but found that it was not nearly so active as the oil. If the statement (Overton) be correct, that the outer layer of cellular endoplasm is composed largely of lecithin and other fatty bodies, this fact may have some bearing on the greater activity of the oily solution. The slowness too with which iodine in fatty combination is excreted, undoubtedly enchances its action on cellular metabolism.

As an illustration of the potency of iodine, it may again be pointed out, that it is possible to kill a patient with advanced pulmonary tuberculosis with 0.5 grain; the absorption of exudate which it causes, setting free sufficient toxin to overwhelm the enfeebled organism. Its use in ordinary cases, even in multiple tuberculous bone lesions is not dangerous. As 0.25 grain once a week in the body of an adult can have no great effect as an antiseptic, its undoubted potency must be due to its action, either 
directly, or indirectly through the thyroid, as an anti-toxin or to its effect as a stimulant to cellular metabolism.

If we can depend upon results such as those given above we shali materially better the prognosis of chorio-retinal oedema, and the effects obtained in these cases and in many others of different type, justify careful investigation of the treatment.

\title{
A CASE OF CONGENITAL GLAUCOMA OF UNUSUAL TYPE
}

BY

\author{
W. G. LaWs \\ NOTTINGHAM
}

THE account of a peculiar case of glaucoma in the BRITISH JournaL of. Ophthalmology for February reminds me of one presenting in some respects similar, and at all events interesting, features, a short note of which may be worth publishing.

M.P. was a girl, aged 15 years, when I saw her in March, 1923. Her right eye had a semi-dilated pupil, surrounded by a ring of uveal pigment; the pupil showed no reaction to light but acted consensually. The fundus presented a striking appearance. The disc was deeply cupped ( $\approx \mathrm{D}$. to $8 \mathrm{D}$.), the retinal veins were enormously distended, the arteries also considerably larger than normal. Tension was about +1 ; the field of vision a small oval $10^{\circ}$ in horizontal, $8^{\circ}$ in vertical diameter, including the macula, and reaching to the blind spot. Central vision was $6 / 12$ (partly). The left eye, except for a small error of refraction, was quite normal.

Some months later Sir R. Cruise saw her. He wrote: "The pupillary and retinal conditions are most striking and interesting, and I thought that at about 11 o'clock the root of the iris looked as if it was adherent far back to the cornea-probably a congenital condition which by occupying sufficient of the circumference of the base of the iris would account for the glaucoma."

Operation (Aug., 1923) seemed to confirm this view. On making a "small flap" at the upper margin of the cornea the point of the keratome as it entered the anterior chamber engaged at once in some filmy tissue lying between the cornea and the iris; as it could not be disengaged the incision was enlarged by small sideway movements instead of by pushing the keratome onwards. When the vertical scleral cuts were made the bleeding was unusually free and persistent. A tendency to iris prolapse necessitated a small iridectomy, and the bleeding was again extremely free. A fort- 